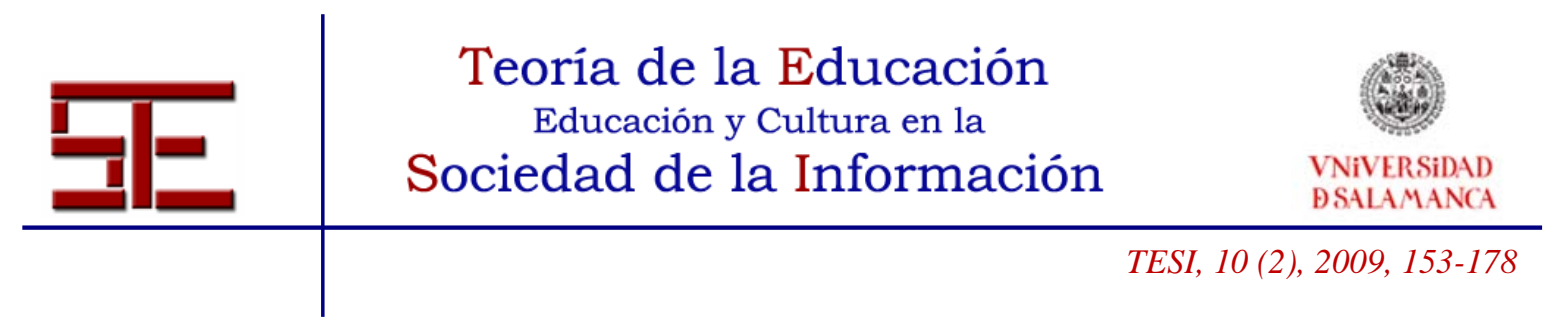

\title{
LA PIZARRA DIGITAL INTERACTIVA COMO RECURSO DOCENTE
}

Resumen: La Pizarra Digital Interactiva (PDI) es un recurso de grandes posibilidades educativas para los docentes. En este artículo se presentan los resultados de distintas investigaciones que han analizado el uso de la PDI a través de distintos programas de formación docente en distintos niveles educativos y áreas curriculares. A diferencia de otros recursos en los que el docente está en un "segundo plano”, una de las ventajas del uso de la PDI es la cercanía al modelo tradicional de enseñanza en la que el profesor presenta los contenidos principales para pasar a las actividades de aprendizaje individuales y grupales. En la sociedad del conocimiento el docente debe adaptar su metodología aprovechando la riqueza de los recursos que ofrece la red y que están disponibles en el aula a través de la PDI, así como la creación de recursos propios integrando objetos multimedia disponibles.

Palabras clave: PDI, Pizarra Digital Interactiva, Recursos docentes. TIC

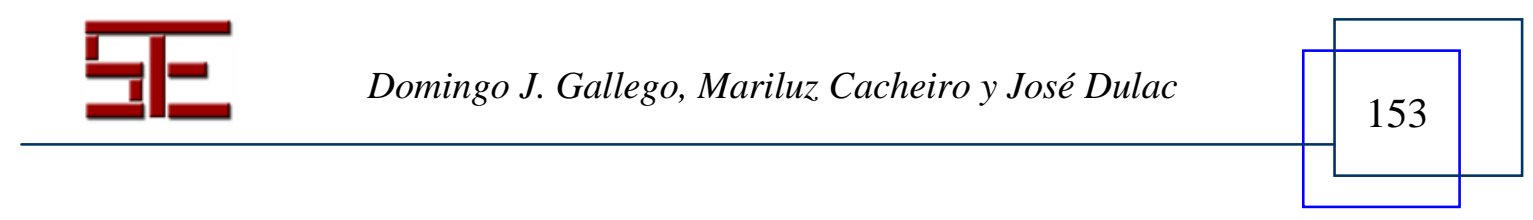




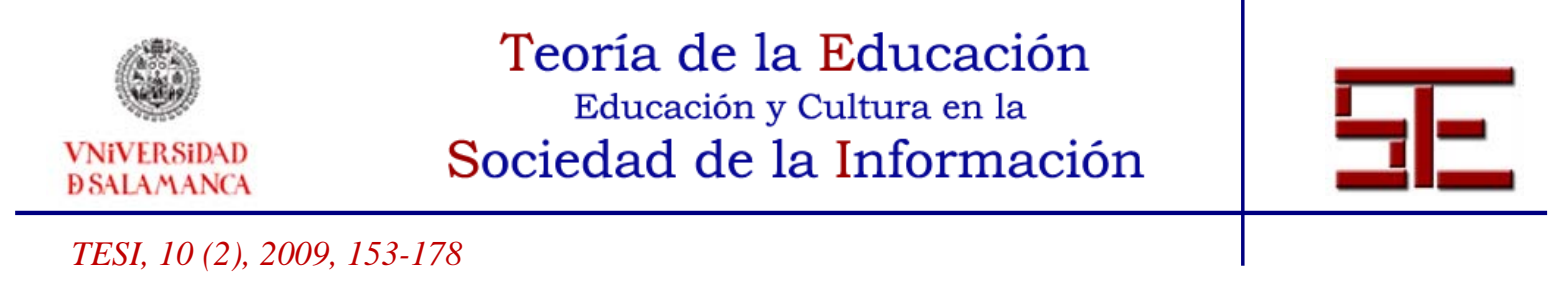

\section{THE INTERACTIVE WHITEBOARD AS A TEACHING RESOURCE}

Abstract: The Interactive Blackboard (PDI-Pizarra Digital Interactiva) is a great educational resource for teachers. This article presents the results of various studies that have examined the use of PDI through various teacher education programs at various educational levels and curricular areas. Unlike other resources on which the teacher is not a key actor, one of the advantages of the use of PDI is its proximity to the traditional model of teaching where the teacher presents the content to go to the main individual and group learning activities. In the knowledge society the teacher must adapt its methodology taking into account the variety of resources offered by the Internet and are available in the classroom through the PDI, and the creation of own resources to integrate multimedia objects available.

Keywords: Interactive Whiteboard, Teaching Resource. ICT.

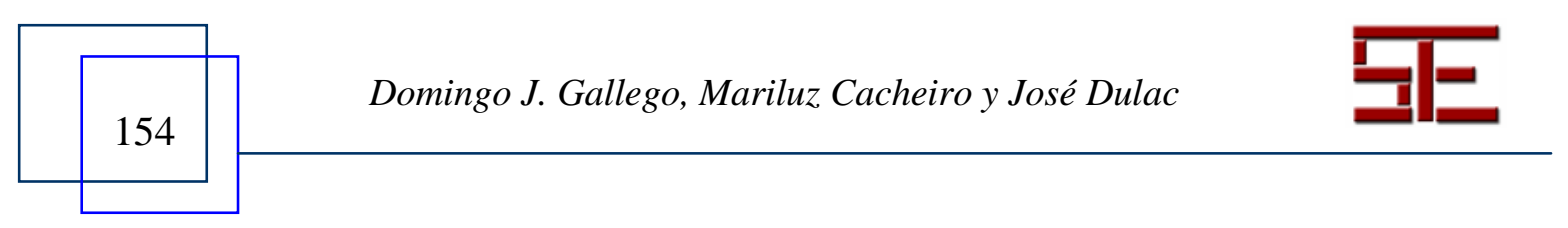




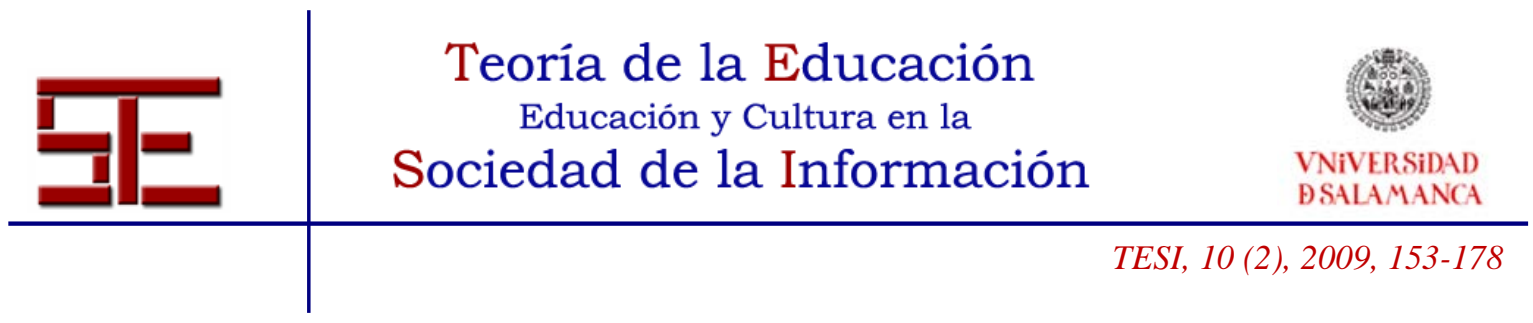

\title{
LA PIZARRA DIGITAL INTERACTIVA COMO RECURSO DOCENTE
}

\author{
Domingo J. Gallego \\ dgallego@edu.uned.es \\ Universidad Nacional de Educación a Distancia. \\ Maria Luz Cacheiro \\ mlcacheiro@edu.uned.es \\ Universidad Nacional de Educación a Distancia.
}

José Dulac

jose@dulac.es

Aula PizarraTIC. Madrid.

\section{1.- INTRODUCCIÓN}

La Pizarra Digital es el recurso tecno educativo que ha irrumpido con más fuerza en el contexto de la educación y formación en el siglo XXI. No cabe duda que está de moda. Todo centro educativo que trata de mostrar el nivel tecnológico de sus enseñanzas, que se encuentra en la punta de la calidad educativa, afirma disponer de un buen número de Pizarras Digitales. En marzo de 2009, durante la impartición de una sesión de trabajo en el doctorado de inteligencia artificial en la Universidad Autónoma de México, UAM, disponíamos en la sala de tres pizarras digitales de diferentes marcas para realizar nuestra exposición y las tareas prácticas con el grupo, de forma que podíamos interrelacionar docentes y discentes con un nuevo formato de comunicación compartida.

Es frecuente encontrarnos noticias en la prensa, televisión e Internet relacionadas con la innovación educativa que suponen las Pizarras Digitales y las inversiones realizadas o planificadas por el organismo autónomo Red.es y las diferentes administraciones educativas en los centros que gestionan o coordinan. Aunque los datos no siempre son tan concretos como nos gustaría y expresan, a veces, más las "buenas intenciones" que los hechos reales y es difícil hacer un cálculo exacto, podríamos indicar que en 2009 unos 8000 centros docentes o de formación de España tienen, al menos, una Pizarra Digital. Para los próximos 5 años, algunas administraciones educativas han mostrado la clara intención de incluir en la dotación básica de todas las aulas una pizarra digital interactiva.

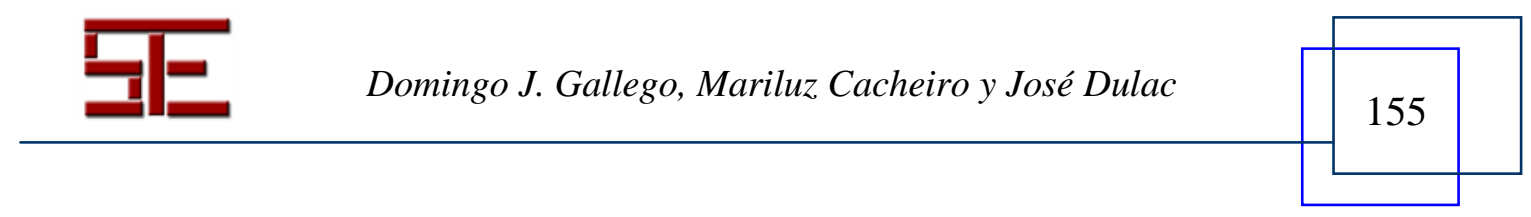




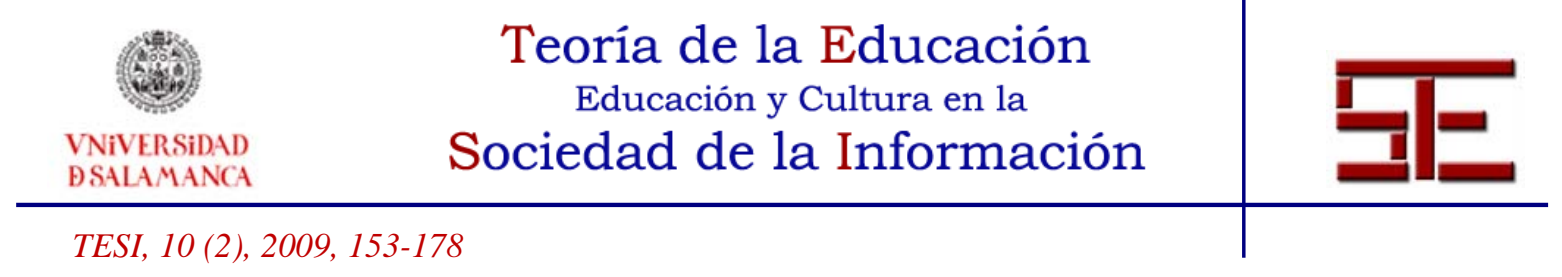

\section{2.- QUÉ ES UNA PIZARRA DIGITAL}

Recordemos brevemente en qué consiste este elemento tecno pedagógico, para que nuestro trabajo quede enmarcado en el contexto de nuestra definición. Hemos participado en varios debates en Seminarios, Congresos, Jornadas y en Internet de concretar una definición. En el foro de DIM (Didáctica y Multimedia) el profesor Pere Marqués proponía estas dos definiciones diferenciando entre Pizarra Digital y Pizarra Digital Interactiva (7/05/07):

Entendemos por Pizarra Digital un sistema tecnológico, generalmente integrado por un ordenador y un video proyector, que permite proyectar contenidos digitales en un formato idóneo para visualización en grupo. Se puede interactuar sobre las imágenes proyectadas utilizando los periféricos del ordenador: ratón, teclado, tableta gráfica...

Podemos definir Pizarra Digital Interactiva como un sistema tecnológico, generalmente integrado por un ordenador, un video proyector y un dispositivo de control de puntero, que permite proyectar *en una superficie interactiva* contenidos digitales en un formato idóneo para visualización en grupo. Se puede interactuar directamente sobre la superficie de proyección.

Esta distinción, no siempre habitual en los documentos e investigaciones, tiene repercusiones prácticas (sobre todo desde una perspectiva económica) y ofrece un abanico específico de ventajas e inconvenientes propios de cada formato.

La PDI ofrece al docente acostumbrado a las pizarras tradicionales de tiza o de rotuladores encontrar un recurso muy cercano a la tradición pedagógica que incorpora las TIC en el aula de manera visible y transparente. Todos los alumnos pueden ver y actuar con los equipos informáticos, individual o grupalmente ante todos sus compañeros. La PDI supera la sensación de “caja negra” y hace posible una amplia variedad de especificaciones y capacidades por ejemplo:

- La manipulación fácil y rápida de textos e imágenes

- Tomar apuntes digitales

- Utilizar la Web y sus recursos ante toda la clase

- Mostrar videos y facilitar el debate

- Utilizar y demostrar diferentes tipos de software

- Guardar notas para la posterior revisión

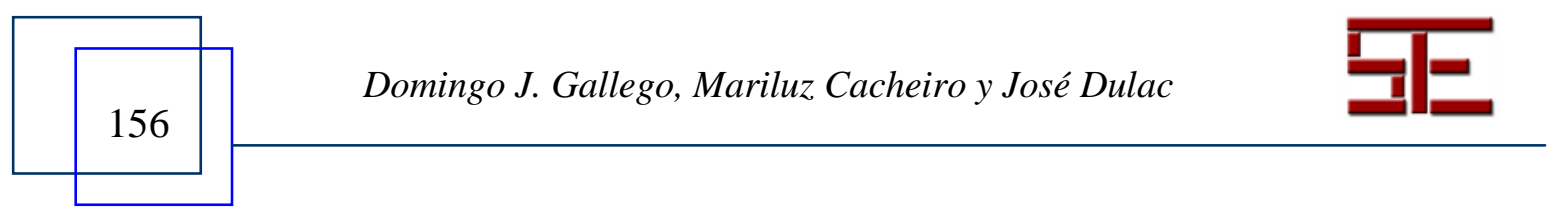




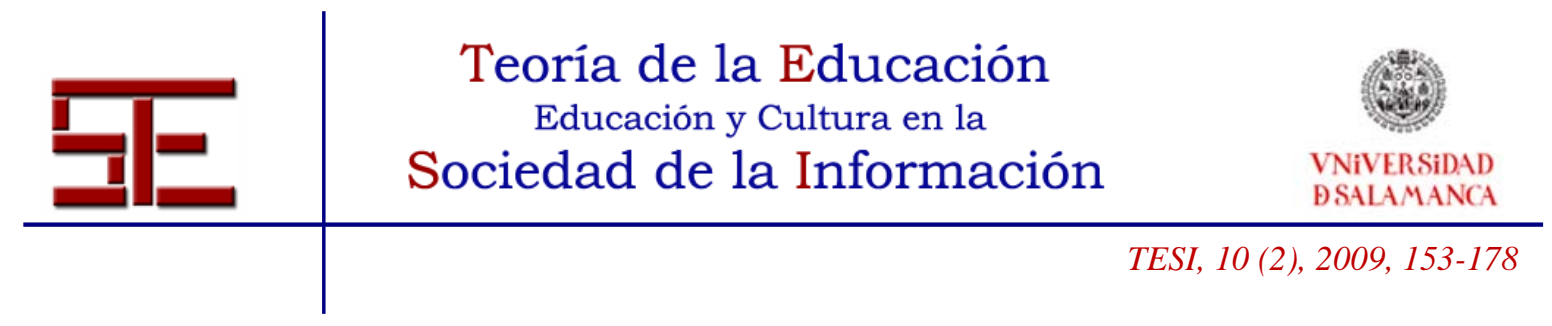

- Utilizar el e-mail para proyectos colaborativos intercentros

- Crear lecciones digitales con imágenes y sonidos

- Escribir y resaltar los aspectos de interés sobre textos, imágenes o vídeos

- Utilizar todas las técnicas y recursos de presentación

- Facilitar la presentación de trabajos de los alumnos

\section{3.- INTERROGANTES ANTE LAS PDI}

En noviembre de 2004, en una de las sesiones de trabajo celebradas en el marco de la Exposición del SIMO, escuchábamos a un conferenciante del Reino Unido explicar las ventajas de la Pizarra Digital y nos comentaba que el Ministerio de Educación de su país había dotado a más de 70.000 centros docentes públicos con este recurso tecnológico. Ese mismo año las escasas y no muy fiables estadísticas que se publicaban en España sobre la existencia total de Pizarras Digitales, incluyendo centros docentes y centros de formación de empresa, nos hablaban de 857 PDI instaladas.

La diferencia entre las cifras de PDI existentes en el Reino Unido y en España era enorme. Desde ese mismo instante decidimos investigar y comprobar si los beneficios educativos de la PDI eran tan importantes como para alcanzar diferencias cuantitativas significativas entre países.

Nos planteamos ante el nuevo recurso una serie de interrogantes, que pedían respuestas bien fundamentadas críticamente:

- ¿En qué medida las Pizarras Digitales son bien recibidas por los docentes?

- ¿Los profesores que tienen PDI en su aula, las encuentran útiles y las integran en sus diseños de sesiones de enseñanza-aprendizaje?

- ¿En qué temáticas y en qué circunstancias las utilizan más?

- ¿El uso de las PDI induce a una progresiva renovación de los métodos docentes?

- ¿En qué circunstancias?

- ¿De qué manera?

- ¿Con la utilización de las PDI mejora de forma significativa el aprendizaje de los alumnos?

- ¿En qué circunstancias?

- ¿Por qué?

- ¿ ¿Se puede relacionar PDI con una mayor motivación de los alumnos?

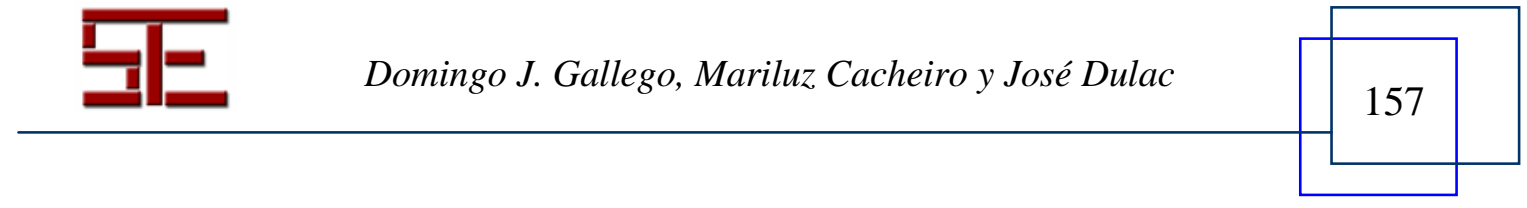




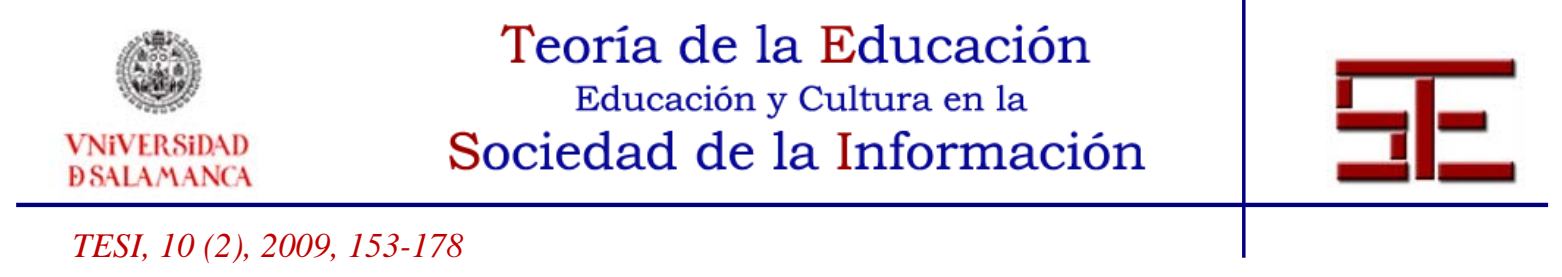

- ¿Las PDI pueden ayudar a los docentes remisos en incorporar las TIC en el aula a integrarse en la sociedad de la información y el conocimiento?

- ¿Qué formación didáctico-tecnológica debe proporcionarse al profesorado para que aproveche las posibilidades didácticas que ofrece este recurso tecnológico?

- ¿Cuáles son las ventajas de la PDI, sus puntos fuertes?

- ¿Cuáles son las desventajas de la PDI, sus puntos débiles?

- ¿Hay buenas prácticas con PDI que puedan transferirse a otros centros, a otros profesores?

\section{4.- INVESTIGACIONES SOBRE PDI EN CONTEXTOS DE LENGUA INGLESA}

Las investigaciones sobre PDI, en lengua inglesa, han alcanzado un nivel importante en el marco de los estudios pedagógicos, aunque queda aún un buen camino por recorrer.

Después de un detenido análisis de los trabajos a los que hemos tenido acceso, destacamos tres centros de investigación sobre PDI con resultados interesantes:

La agencia gubernamental del Reino Unido BECTA, British Educational Communications and Technology Agency; La agencia gubernamental NCEF, National Clearinghouse for Educational Facilities, agencia del Departamento de Educación de Estados Unidos. La empresa canadiense SMART Technologies que ha dedicado un gran esfuerzo a promover y recoger investigaciones, experiencias, buenas prácticas y hacerlas accesibles a los docentes.

Incluimos en la Bibliografía algunas de las referencias de estas tres instituciones que nos parecen más significativas.

La clasificación y organización de estas investigaciones sigue modelos distintos.

BECTA prefiere organizar temáticamente las investigaciones, destacando algunos aspectos sencillos y útiles para los docentes. NCEF distingue dos categorías, por una parte, los libros y otros medios y, por otra, los artículos de revistas especializadas. Las Bases de Datos que ofrece Smart Technologies parece preferir una clasificación cronológica y/o geográfica de los trabajos.

El primer tema que nos llama la atención es cómo los investigadores destacan las ventajas generales de las PDI porque:

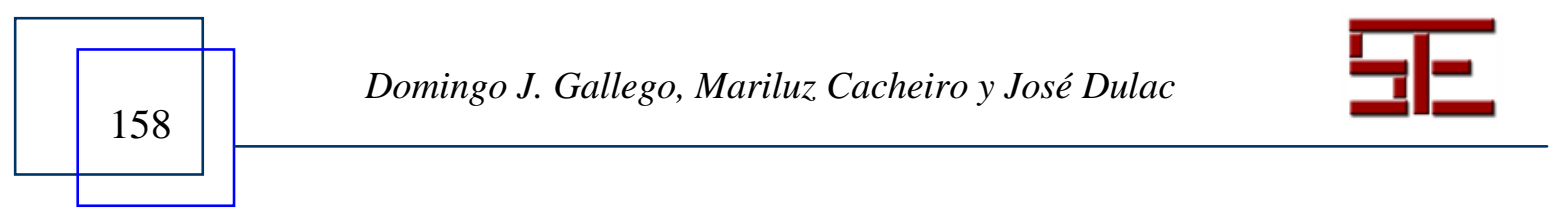




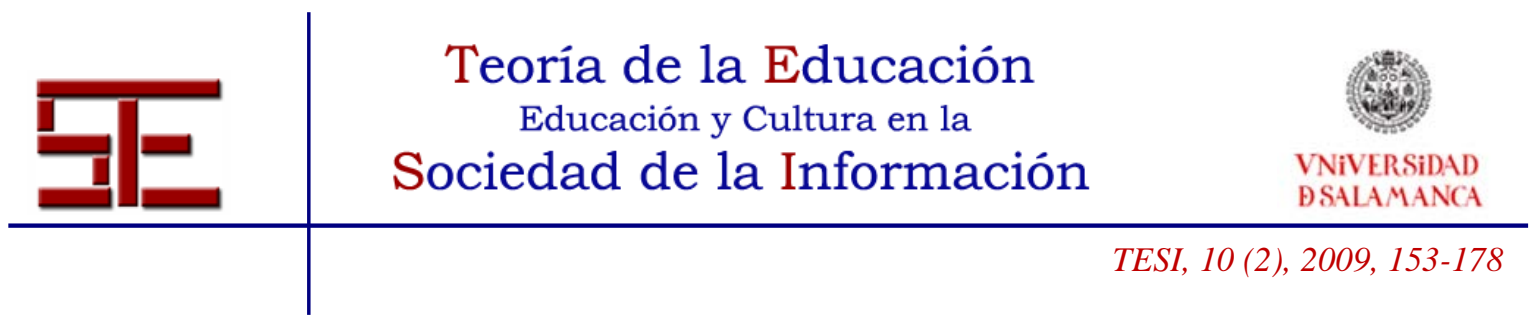

- Facilitan una mayor oportunidad para la interacción y el debate en el aula, especialmente si comparamos con otros recursos TIC (Gerard y Otros, 1999).

- Es un recurso muy versátil, con aplicaciones para todas las edades y todas las áreas curriculares. (Smith, 1999). Aumenta la disponibilidad de tiempo permitiendo al docente presentar con facilidad y eficacia recursos de internet o de otra fuente informática. (Walker, 2003).

- Aumenta la satisfacción y la motivación tanto en los docentes como en los discentes, gracias al uso de fuentes más variadas, dinámicas y divertidas. (Levy, 2002).

En segundo lugar las PDI significan una ventaja para los alumnos:

- Reduce la necesidad de tomar apuntes, ya que todo lo que aparece en la pantalla textos, dibujos, imágenes, esquemas, etc. puede imprimirse.

- Aumentan las oportunidades de participación y colaboración, ayudando a desarrollar en los alumnos las destrezas personales y sociales. (Levy, 2002).

- Se puede tener en cuenta los distintos estilos de aprendizaje de los alumnos ya que los profesores pueden acudir a muchas y variadas fuentes y recursos para responder a las necesidades específicas del alumno. (Bell, 2002).

- Capacita a los estudiantes para ser más creativos en sus presentaciones en clase aumentado su autoconfianza y su auto concepto. (Levy, 2002).

- Aumenta la diversión y la motivación.

- Los alumnos pueden comprender conceptos más complejos gracias a las presentaciones, más claras, más dinámicas y más eficientes. (Smith, 2001).

- Las PDI permiten el acceso al ordenador sin utilizar el teclado, gracias a la macro pantalla táctil, facilitando el uso de la informática a niños pequeños y a estudiantes de educación especial o con minusvalías. (Goodison, 2002).

En tercer lugar las PDI se configuran como un recurso didáctico con muchas ventajas para los docentes:

- Facilita a los profesores el uso de las TIC integrándolas en su diseño curricular de aula mientras se dirigen a toda la clase manteniendo el contacto visual.

(Smith, 2001).

- Fomenta la espontaneidad y la flexibilidad, facilitando a los profesores una panoplia muy amplia de recursos en texto, en gráficos, en sonidos y en imágenes (Kennewell, 2001).

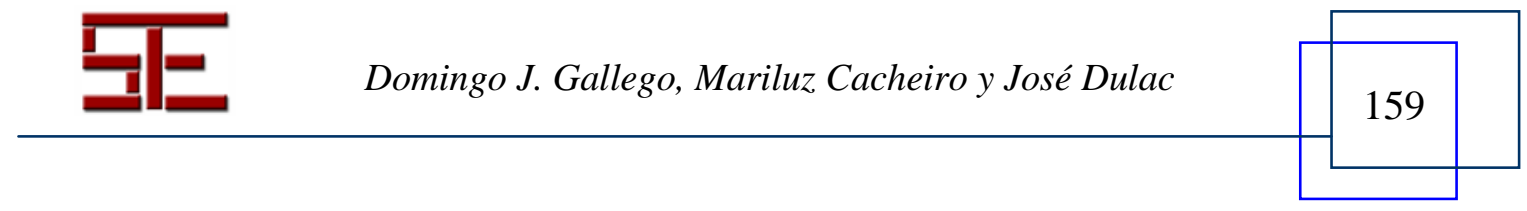




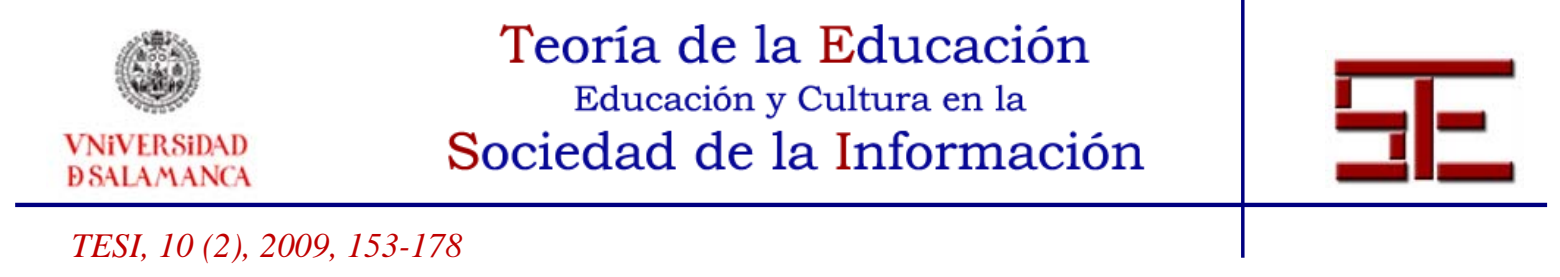

- Facilita a los profesores el compartir y utilizar varias veces materiales didácticos. (Glover y Miller, 2001).

- Posibilita a los profesores el conservar e imprimir lo que está en la pizarra, incluyendo las notas realizadas durante la clase, facilitando la revisión. (Walker, 2002).

- Las PDI son fáciles de utilizar y permiten una presencia fácil eficaz del ordenador o Internet en cualquier tema de estudio. (Smith, 2001).

Inspira a los docentes a cambiar su manera de enseñar incluyendo las TIC en su proyecto de aula y les anima en su desarrollo y progreso personal. (Smith, 1999).

En cuarto lugar destacamos la amplia temática que se ha investigado relacionando la PDI con aspectos y materias muy diferentes:

Juegos para ordenador

Enseñanza universitaria

Enseñanza secundaria

Enseñanza en educación primaria e infantil

Enseñanza de la historia

Enseñanza de la lengua

Enseñanza de las matemáticas

Enseñanza de la música

Enseñanza de las ciencias

Educación especial

Formación de profesores

\section{5.- IBERIAN RESEARCH PROJECT}

También en España hemos desarrollado una serie de investigaciones con resultados esperanzadores para los partidarios de este recurso educativo. En el año 2005 iniciamos la investigación el Iberian Research Project con cinco objetivos clave:

1. Revisar y analizar la literatura pedagógica y las investigaciones realizadas sobre PDI

2. Identificar las posibilidades pedagógicas de la PDI en la praxis docente.

3. Diseñar, implementar y evaluar modelos formativos para los profesores y alumnos usuarios de PDI.

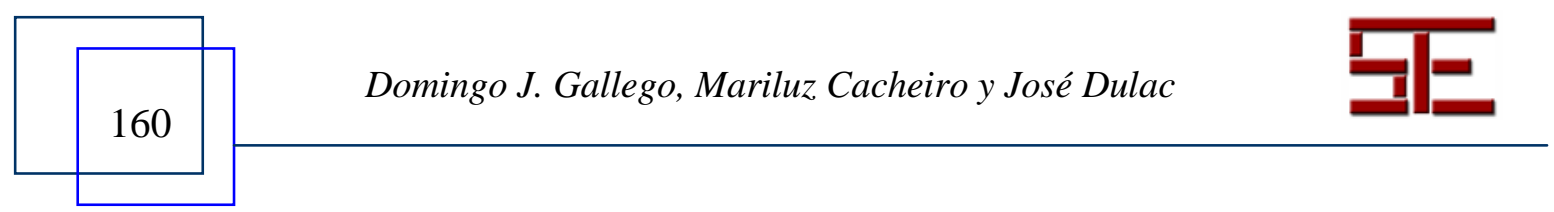




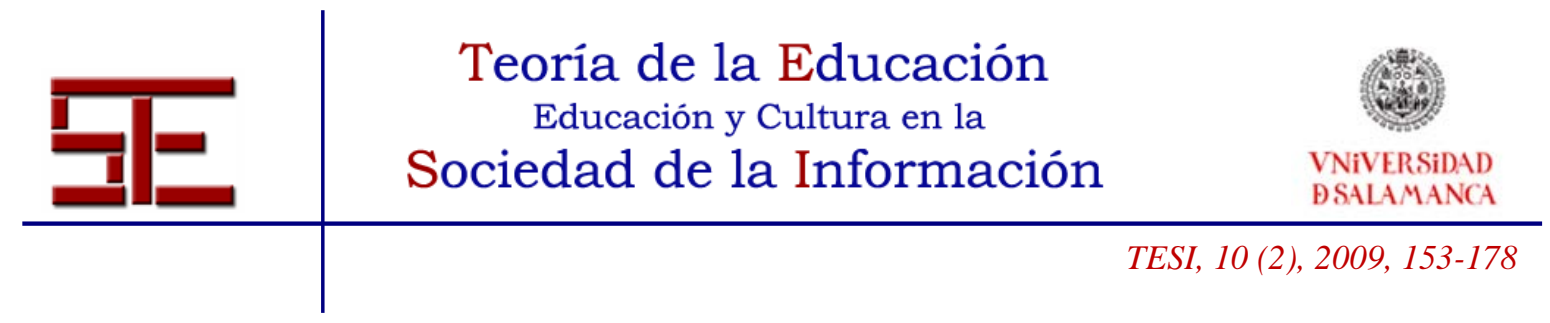

4. Calibrar los resultados obtenidos por la introducción en España de las PDI en diferentes niveles educativos, educación infantil, educación básica, educación secundaria, módulos formativos, universidad y formación en instituciones y empresas

2. Proponer un nuevo modelo pedagógico adaptado a las nuevos recursos y herramientas informáticas, multimedia e interactivas.

El proyecto Iberian Research Project se llevó a cabo de manera simultánea con el apoyo de GroupVision y SMART Technologies Inc. (Gallego y Dulac, 2005).

- En Madrid coordinado por Domingo J. Gallego y José Dulac, UNED con la colaboración

- del Grupo Pizarra,

- En Cataluña coordinado por Pere Marqués, Universidad Autónoma de Barcelona,

- En Navarra y el País Vasco, coordinados por Charo Repáraz y Angel Sobrino,

- Universidad de Navarra y

- En Portugal, coordinado por Antonio Rodrigues.

Las metodologías de acción fueron diferentes y también los resultados obtenidos.

En el grupo que investigamos en la Comunidad de Madrid, con la participación de diez centros docentes públicos de Primaria y Secundaria y ciento veinte profesores destacamos un resultado fundamental. La formación tecno pedagógica que reciben los profesores resulta el elemento clave para conseguir la integración positiva en el aula de la PDI, aprovechando todas sus potencialidades. Se dedicaron treinta horas de formación presencial a dos docentes de cada centro que, posteriormente, compartían con sus compañeros los aprendizajes.

Describimos brevemente los instrumentos para la recogida de datos que utilizamos en la investigación realizada en la Comunidad de Madrid y algunas de las conclusiones que la investigación nos ofrece.

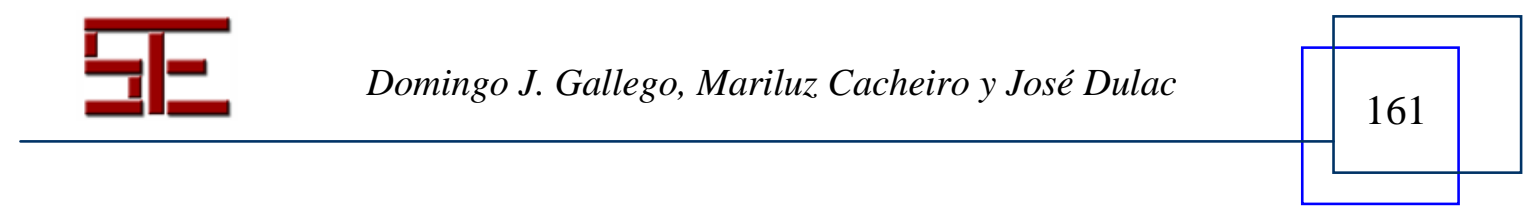


Teoria de la Educación

Educación y Cultura en la

Sociedad de la Información

\begin{tabular}{|c|c|}
\hline \multicolumn{2}{|c|}{ INSTRUMENTOS DE LA INVESTIGACIÓN } \\
\hline INSTRUMENTOS UTILIZADOS & CANTIDAD \\
\hline Entrevistas con los coordinadores & 20 \\
\hline $\begin{array}{l}\text { Entrevistas con los profesores } \\
\text { colaboradores }\end{array}$ & 18 \\
\hline $\begin{array}{l}\text { Observación directa en visitas a las aulas } \\
\text { en sesiones prácticas }\end{array}$ & 42 \\
\hline $\begin{array}{l}\text { Ficha de seguimiento de las sesiones en } \\
\text { el aula }\end{array}$ & 603 \\
\hline Encuesta final a profesores participantes & 72 \\
\hline Encuesta final a alumnos & 47 \\
\hline Fotografías & 156 \\
\hline Vídeos & 5 \\
\hline
\end{tabular}

Citamos ahora algunas de las conclusiones obtenidas: 


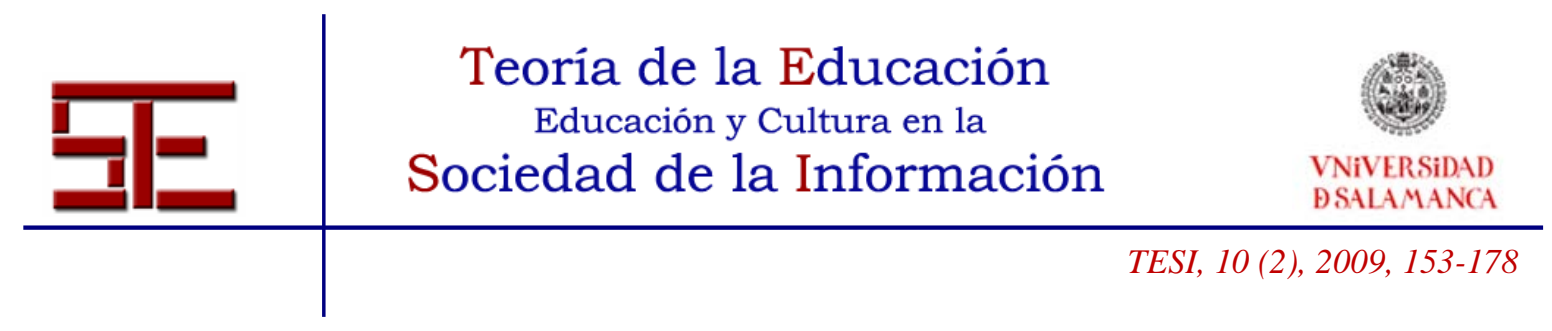

\section{COMODIDAD DE USO \\ Valoración media 9,2}

Es una herramienta que resulta cómoda para los docentes.

\section{En 242 sesiones de un total de 600 se califica con la nota máxima la comodidad de uso}

$\square$ La PD es cómoda de usar

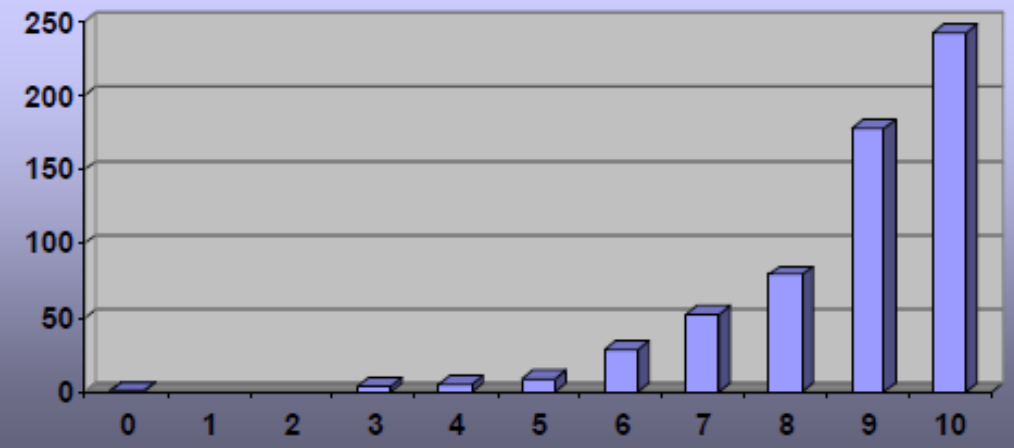

Se trata de un recurso fácil de usar y al que los docentes y discentes se acostumbran con rapidez. Que en 242 sesiones de enseñanza-aprendizaje se haya calificado con la máxima puntuación y que la media alcanzada sea 9,2 demuestra sobradamente esta característica.

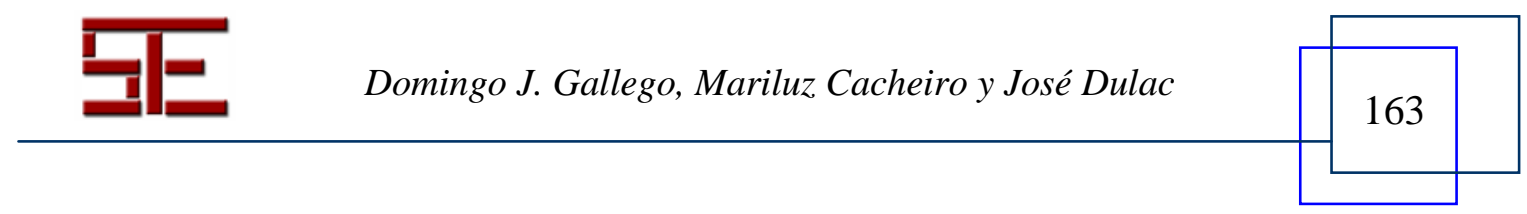


Teoria de la Educación

Educación y Cultura en la

\section{AYUDA PARA EL PROFESOR}

Una gran mayoría de profesores han considerado que, en las sesiones evaluadas, la Pizarra Digital les ha ayudado

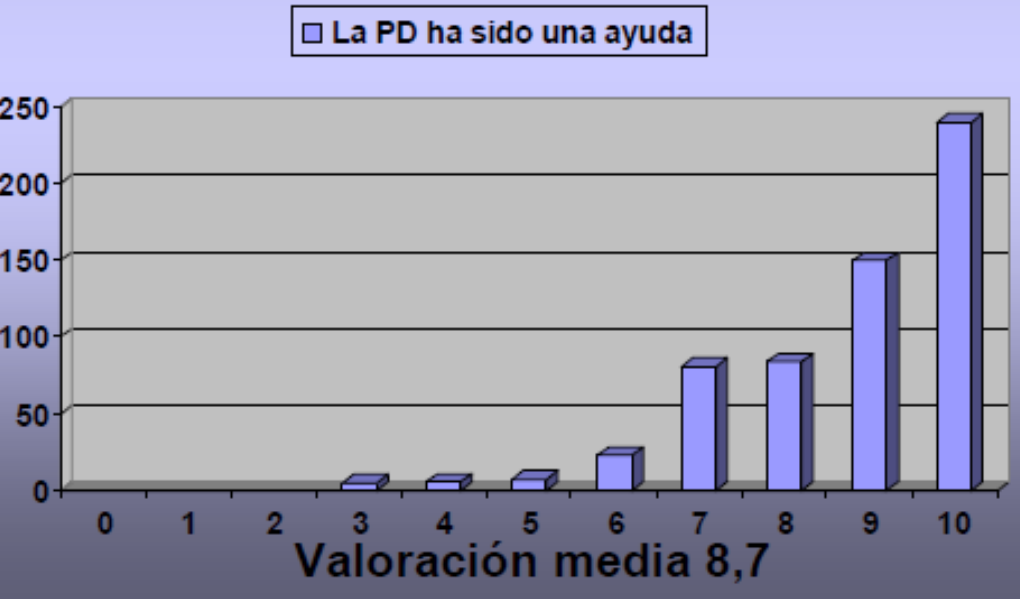

La media obtenida de 8,7 es importante. Demuestra que el profesor percibe la Pizarra Digital como una ayuda en su tarea. 


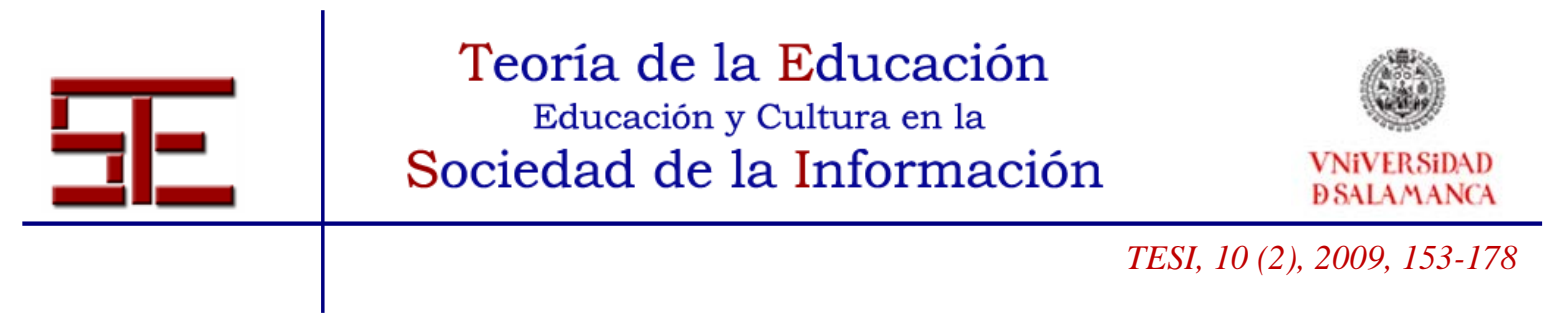

\section{MOTIVACIÓN DEL PROFESOR}

Valoración media 8,9

Es una herramienta que motiva e ilusiona.

I De un total de 600 respuestas 450 obtienen una calificación sobresaliente de 9 ó 10.

$\square$ Motivación del profesor

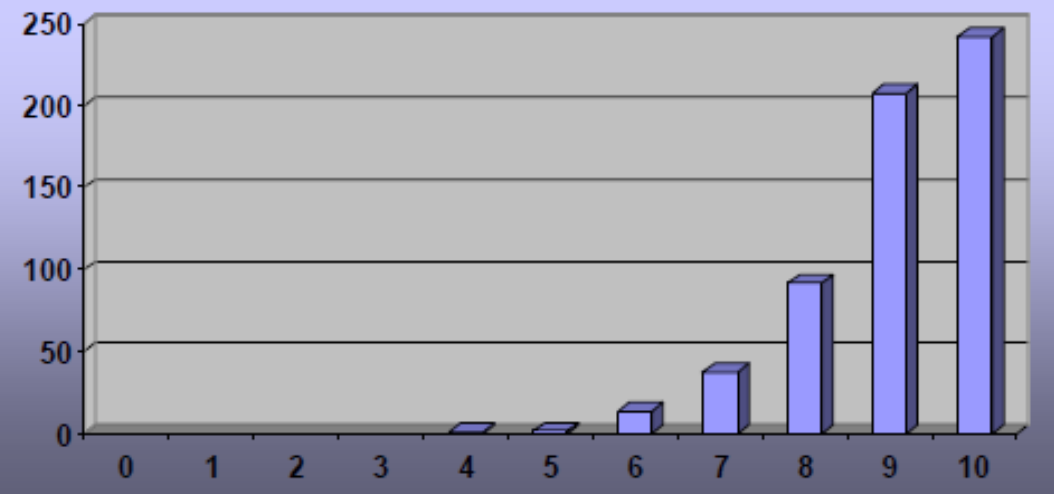

Nos encontramos con una herramienta que motiva e ilusiona a los docentes, con una media de 8,9 de las respuestas.

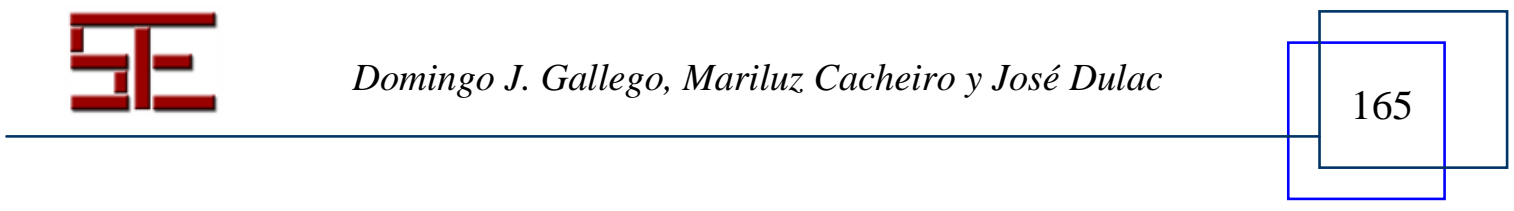


Teoria de la Educación

Educación y Cultura en la

Sociedad de la Información

\section{MOIIVACIÓN DEL ALUMNO \\ Valoración media 9,25}

Es fácil suponer que los alumnos serían fácilmente motivados con la Pizarra Digital.

Las respuestas son de los profesores y corresponden a 600 sesiones evaluadas.

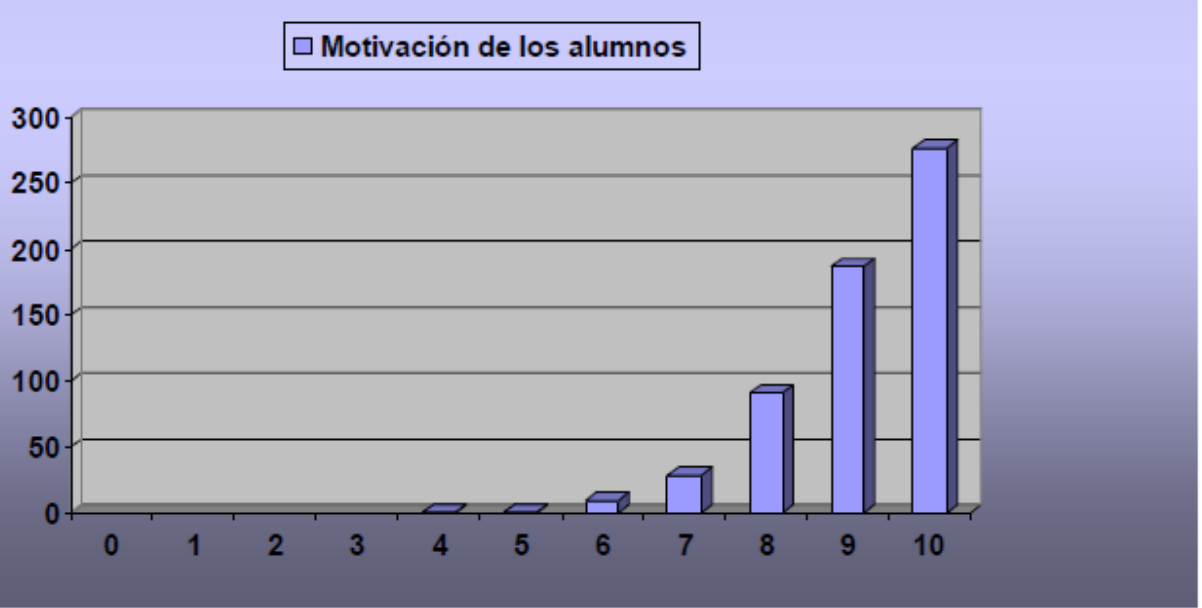

La puntuación obtenida por las respuestas acerca de la motivación de los alumnos es aun más notable, 9,25 y corresponden a 600 sesiones evaluadas.

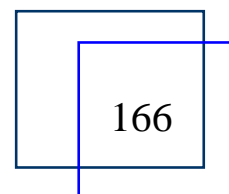




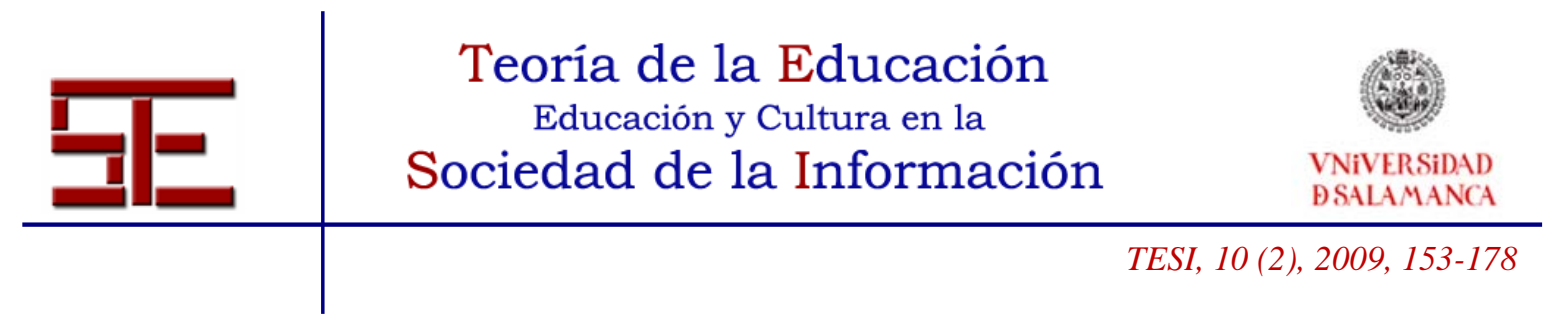

\section{MEJORA EL APRENDIZAJE Valoración media 8,3}

En 454 ocasiones (un $76 \%$ ) se evalúa la mejora del aprendizaje con una calificación de 8, 9 ó 10.

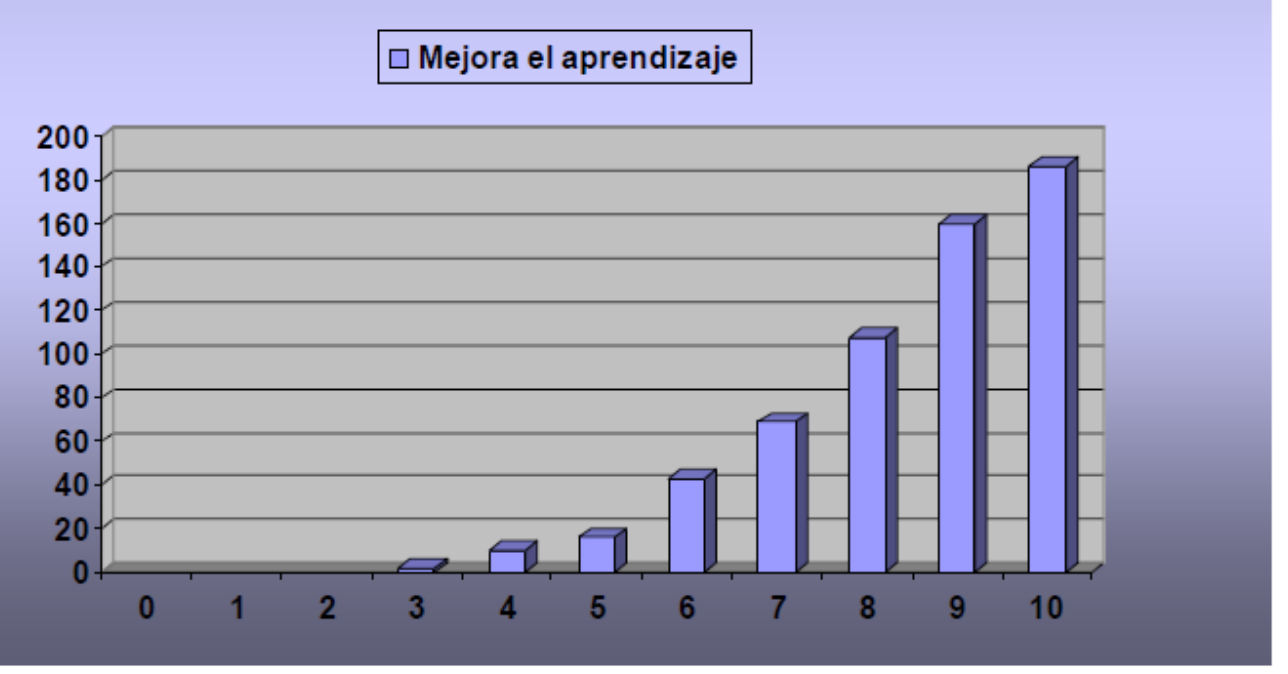

Podemos responder que si mejora el aprendizaje del alumno con la PDI. Y de forma significativa. Un 76\% de las respuestas señala 8, 9 o 10, las calificaciones más altas. 
Teoria de la Educación

Educación y Cultura en la

Sociedad de la Información

\section{PARTICIPACIÓN DE LOS ALUMNOS}

\section{Valoración media 8,6}

I Según los profesores se propicia la participación de manera muy notable y, por lo tanto, un papel mucho más activo de los alumnos lo que facilitará la enseñanza y mejorará el aprendizaje.

\section{$\square$ Participación de los alumnos}

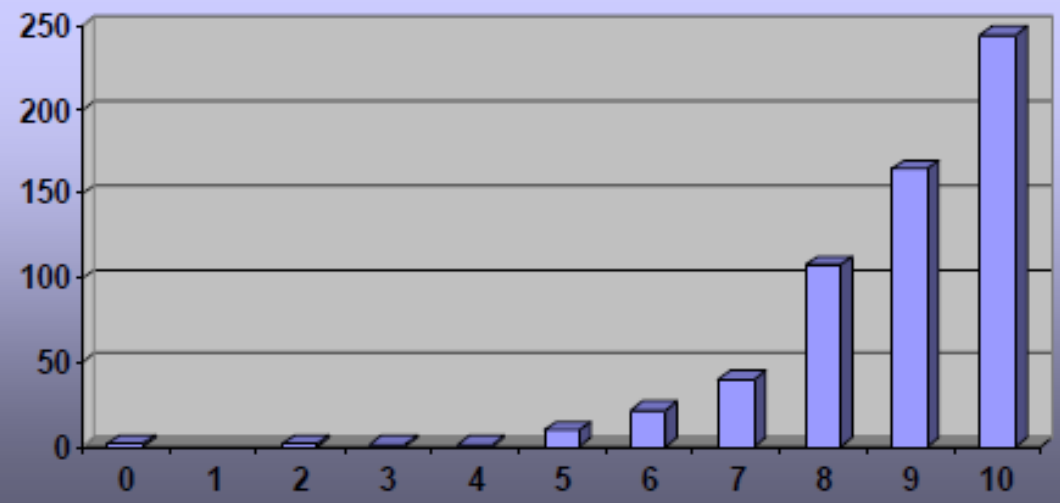

Algunos críticos señalan como una desventaja de las PDI la falta de participación del alumno. Todo parece que es controlado por el docente. Los resultados obtenidos demuestran lo contrario. La PDI, correctamente utilizada, fomenta la participación y actividad de, los alumnos.

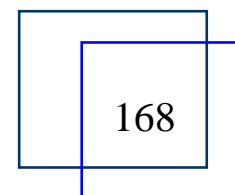




\begin{tabular}{c|cc} 
& $\begin{array}{c}\text { Teoría de la Educación } \\
\text { Educación y Cultura en la } \\
\text { Sociedad de la Información }\end{array}$ & $\begin{array}{c}\text { VNiVERSiDAD } \\
\text { DSALAMANCA }\end{array}$ \\
\hline & & TESI, 10 (2), 2009, 153-178
\end{tabular}

\section{I]Los profesores califican la PDI en su totalidad como} buena y muy buena.

I Supone un éxito sin precedentes en el grado de aceptación y eficacia en la utilización de un recurso educativo en las aulas.

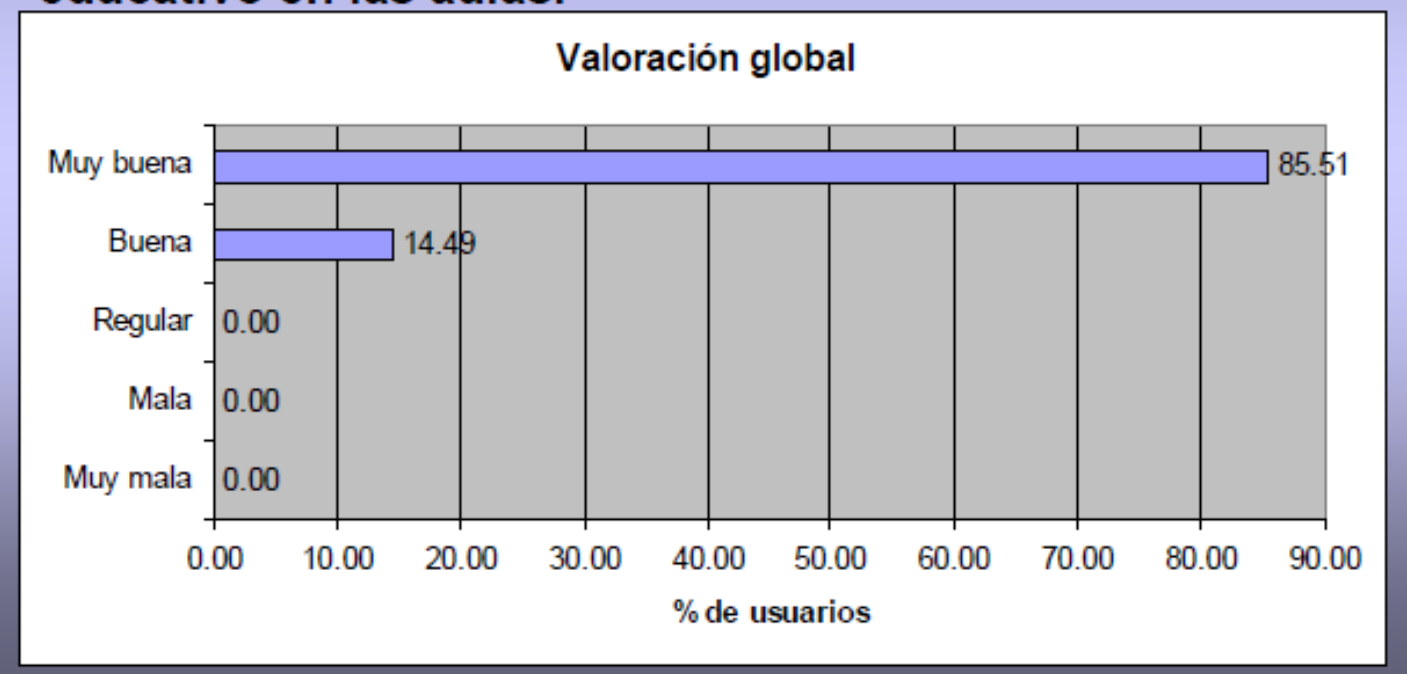

Como resumen final se preguntó a los docentes la calificación en conjunto de la PDI como recurso didáctico y la respuesta fue muy clara, el $85,61 \%$ la calificaron de muy buena y 14,49 como buena.

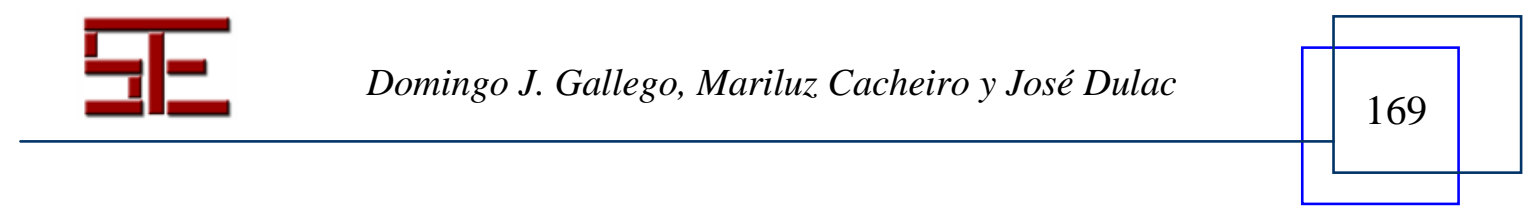


Teoria de la Educación

Educación y Cultura en la

Sociedad de la Información

- Se preguntó a los alumnos si consideraban que con la utilización de la Pizarra Digital habían aprendido más y mejor.

Elayoritariamente respondieron que si, el 91,8 \%.
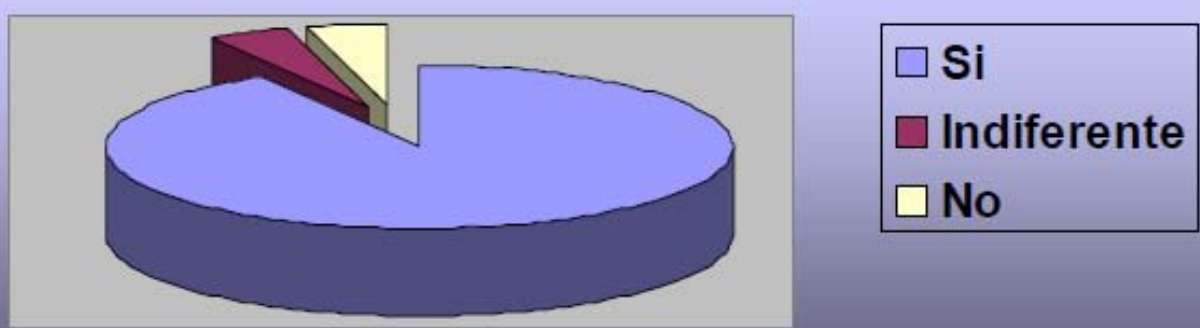

Cuando se preguntó a los alumnos si con el uso de la PDI habían aprendido mejor el 91\% respondieron que sí.

\section{6.- OTRAS INVESTIGACIONES SOBRE PDI EN ESPAÑA}

Cuando ponemos a disposición de los docentes herramientas eficaces y de calidad acompañadas de una adecuada formación metodológica se potencia rápidamente la creación de contenidos por parte de profesores y alumnos. En esta línea de trabajo centrada en la formación del profesorado, Dulac (2006) ha llevado a cabo una investigación con la red de centros continuando el proyecto Iberian Research Project para analizar los aspectos metodológicos que implica el uso de la Pizarra Digital. Los resultados obtenidos por este trabajo de campo fueron:

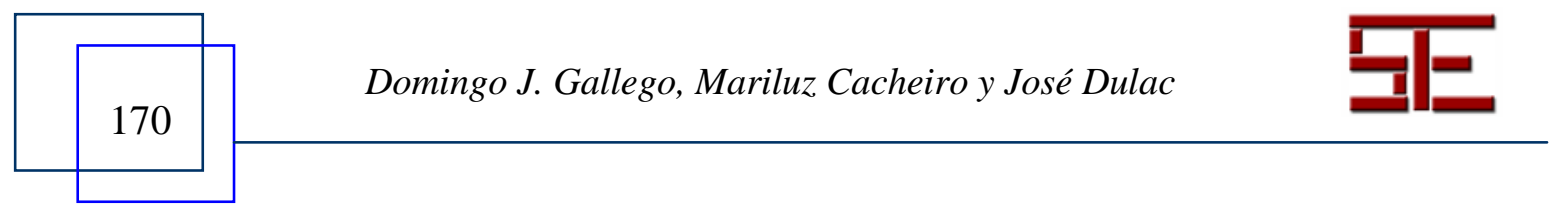




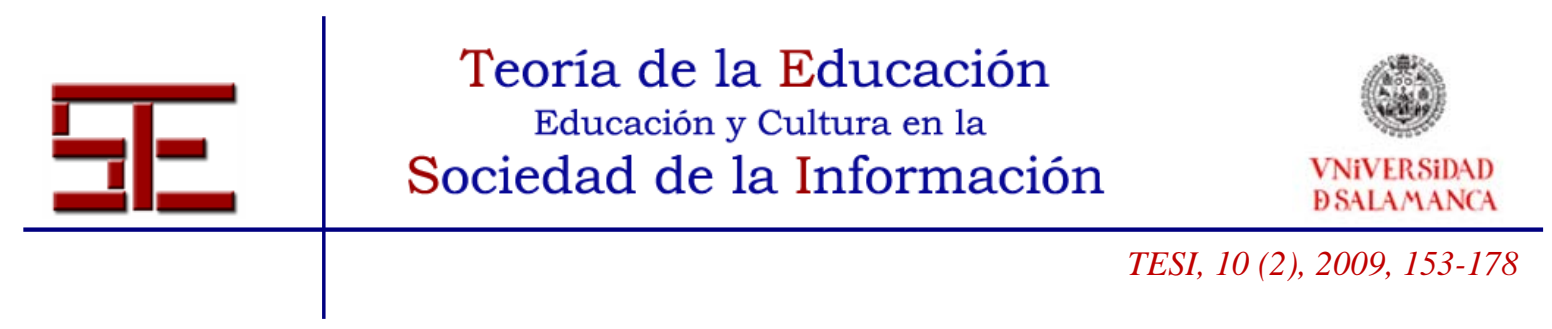

- La Pizarra Digital es una herramienta aceptada por la generalidad del profesorado por tres razones fundamentales: Es de fácil uso, mejora rápidamente la enseñanza y el aprendizaje y potencia la creatividad.

- Si a esta aceptación generalizada acompañamos una adecuada formación metodológica de los profesores usuarios, habremos conseguido integrar proyectos de éxito en los que el cambio metodológico se verá acompañado de la integración curricular de las tecnologías de la información y la comunicación.

La Pizarra Digital es una herramienta del profesor que le permite ubicarse correctamente ante el reto continuo que suponen los avances tecnológicos y ubicar a sus alumnos en una actitud más participativa de su aprendizaje:

- La formación para los profesores usuarios de Pizarra Digital debe comprender aspectos técnicos, metodológicos, interactivos y creativos.

- Los contenidos con una presentación multimedia, interactiva y creativa son más fácilmente generadores de conocimiento por parte de los alumnos, por lo que el aprendizaje requiere menor esfuerzo.

- Una metodología adecuada para la utilización de la Pizarra Digital no debe ignorar el potencial creativo de los alumnos de cualquier edad, área o nivel educativo ya que supone una importante mejora en los niveles de aprendizaje.

- Casi el 50\% de los profesores participantes en la investigación aportaban una experiencia de más de 2 años en la utilización de la Pizarra Digital. Empezamos a descartar que el entusiasmo inicial sea uno de los factores determinantes del éxito de los proyectos desarrollados con la Pizarra Digital.

- La versatilidad de la herramienta hace que sea una constante una actitud reflexiva sobre la mejora de la metodología empleada. Se consigue así una adaptación metodológica coherente con una integración curricular de las tecnologías de la información y la comunicación.

- La mayor motivación de profesores y alumnos usuarios de la Pizarra Digital lleva consigo una mejora de la autoestima y una participación más activa en la dinámica de la clase.

- La inversión económica que hay que realizar en las aulas para dotarlas de una Pizarra Digital y los buenos resultados que se generan de manera inmediata nos permiten afirmar que estamos ante uno de los modelos más eficaces para la integración de las tecnologías de la información y la comunicación en la educación.

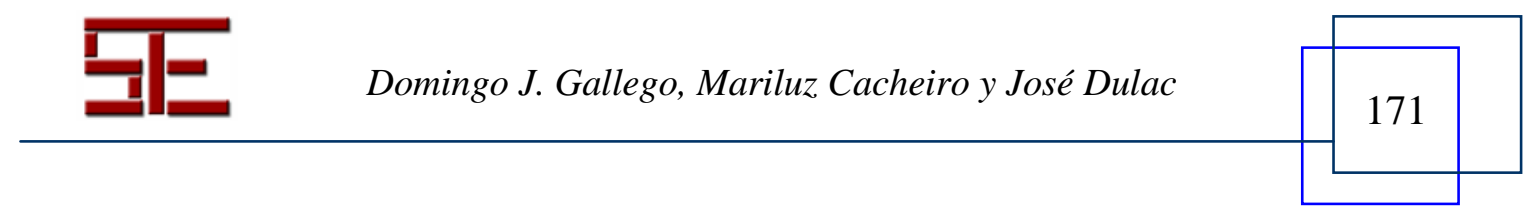




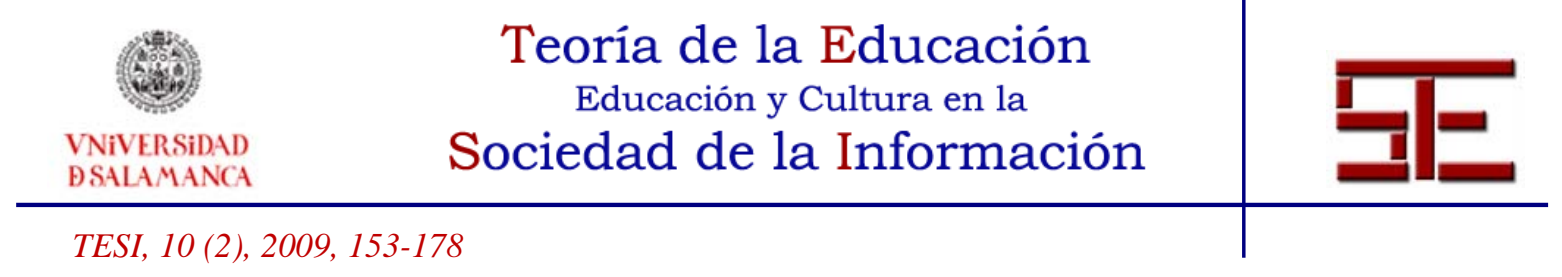

Desde el Foro Pedagógico de Internet de la Fundación Encuentro se ha aplicado el modelo CAIT (Constructivo, Autorregulado, Interactivo y Tecnológico) en la integración de la Pizarra Digital en los procesos de sensibilización, elaboración, personalización, aplicación y evaluación (Pradas, 2005).

Marqués (2008) ha recopilado numerosas experiencias de uso de la Pizarra Digital Interactiva en distintas áreas del conocimiento y está llevando a cabo en la actualidad nuevas investigaciones analizando nuevos aspectos de la PD. Describe muchas aportaciones de la pizarra digital a los procesos de enseñanza y aprendizaje entre las que destacamos las siguientes:

- Aumenta la participación de los alumnos. Les suele gustar salir a presentar materiales y trabajos. Permite compartir imágenes y textos. Facilita el debate.

- Aumenta la atención y retentiva de los estudiantes, al participar más.

- Motiva, aumenta el deseo de aprender de los estudiantes

Aumenta la comprensión: multimedialidad, más recursos disponibles para mostrar y comentar, mayor interacción. Permite visualizar conceptos y procesos difíciles y complejos.

- Facilita el tratamiento de la diversidad de estilos de aprendizaje: potencia los aprendizajes de los alumnos de aprendizaje visual, alumnos de aprendizaje cenestésico o táctil (pueden hacer ejercicios donde se utilice el tacto y el movimiento en la pantalla).

- Ayuda en Educación Especial. Pueden ayudar a compensar problemas de visión (en la PDI se puede trabajar con caracteres grandes), audición (la PDI potencia un aprendizaje visual), coordinación psicomotriz (en la PDI se puede interactuar sin ratón ni teclado).

- El profesor se puede concentrar más en observar a sus alumnos y atender sus preguntas (no está mirando la pantalla del ordenador).

- Aumenta la motivación del profesor: dispone de más recursos, obtiene una respuesta positiva de los estudiantes.

- El profesor puede preparar clases mucho más atractivas y documentadas. Los materiales que vaya creando los puede ir adaptando y reutilizar cada año.

En estos proyectos de investigación han generado un alto potencial creativo en los profesores participantes. Para alcanzar niveles de creatividad eficaces hay que formar a

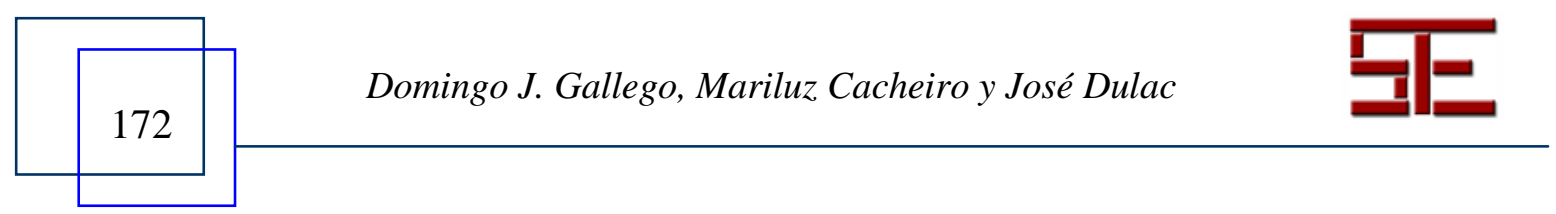




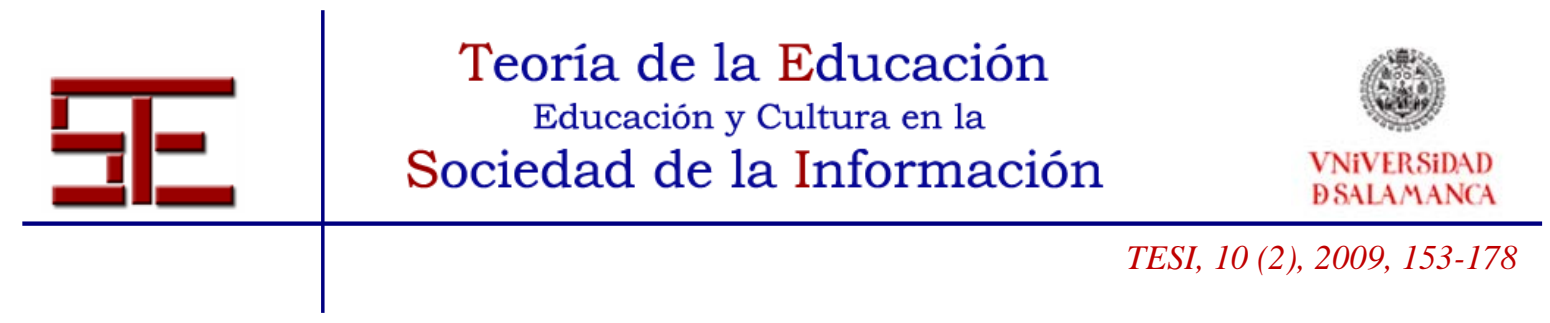

los docentes con habilidades metodológicas y también creativas. Algunas de las líneas establecidas para la continuación de la investigación en el uso pedagógico de la Pizarra Digital incluyen estudios sobre los nuevos formatos y los nuevos modelos de PDI y su coordinación con otros recursos como la cámara de documentos, las WII etc, (Alconada et al, 2007):

- PD y TabletPC

- Modelos Pedagógicos para la PD - CAIT

- Los idiomas y la PD

- NEE y PD

- $\quad$ BITs de Inteligencia y PD

- La PD en el ámbito universitario

- PD y marketing en los centros educativos

- Creatividad con PD

\section{7.- NUESTRA PROPUESTA PEDAGÓGICA}

Todas nuestras investigaciones han tenido y tienen una característica en común: se basan en la priorización de la formación de los profesores usuarios. Es dónde hemos realizado los mayores esfuerzos. Desde el primer momento tuvimos muy claro que trabajar con una Pizarra Digital era algo aparentemente fácil, todos los profesores podían hacerlo sin tener demasiadas dificultades. Comprobamos rápidamente que para sacar el máximo provecho a la herramienta con su gran potencial informático, multimedia, interactivo y ante todo didáctico, se precisaba una formación.

El diseño de los módulos formativos ha variado mucho desde nuestros primeros modelos. Detectamos que el trabajar con una herramienta interactiva de gran tamaño, haciendo las presentaciones para toda la clase nos quedábamos, en la mayoría de los casos, en excelentes presentaciones multimedia lejos de la interacción de los objetos y contenidos para adaptarlos a las necesidades del aprendizaje de nuestros alumnos. Con la facilidad de utilización del software que incorporan las Pizarras Digitales, los profesores teníamos al alcance de un clic gran cantidad de utilidades para integrar motivadores efectos multimedia en nuestras presentaciones en las aulas.

Fue necesario dirigir y poner a trabajar a un grupo de expertos en la utilización de tecnología educativa para investigar sobre los modelos pedagógicos más eficaces. No resultó fácil el interiorizar en el trabajo cotidiano del aula modelos interactivos para

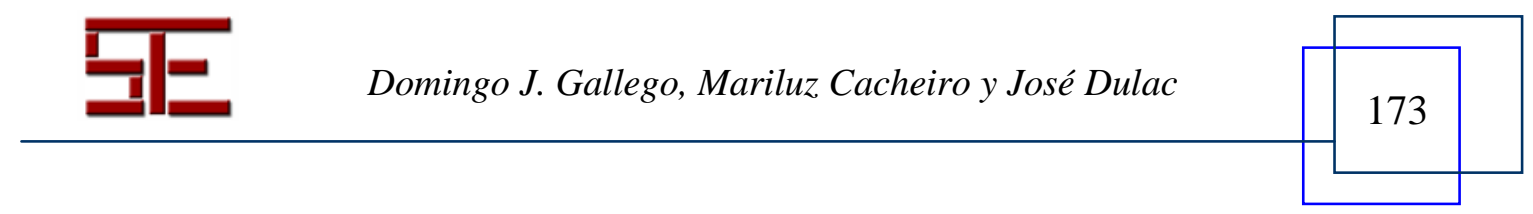




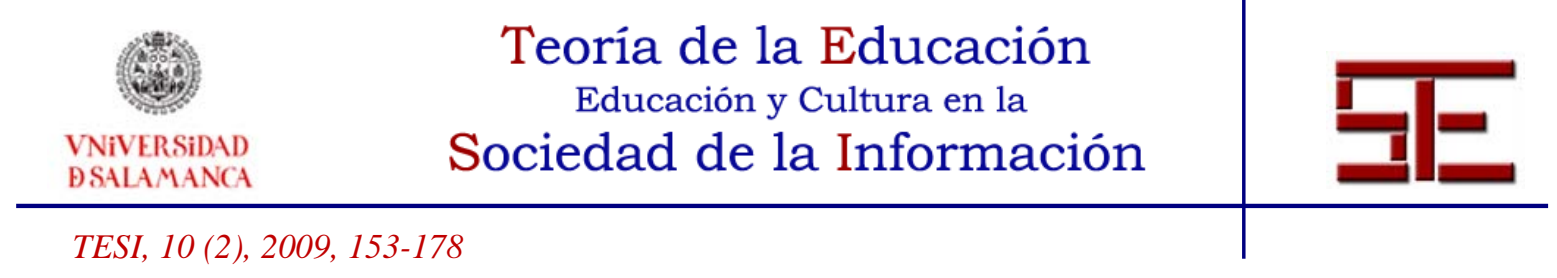

presentaciones en una pantalla de gran tamaño. Exigía, incialmente, un gran esfuerzo y tiempo en la preparación de los contenidos para el aula. Incorporamos algunas de las habilidades metodológicas que habíamos valorado como más eficaces en la enseñanza.

Básicamente consistía en:

1-Mejorar la motivación previa de los alumnos ente la propuesta de una clase en la que utiliza la Pizarra Digital.

2-Captar la atención de los alumnos sobre las propias explicaciones del profesor y sobre la presentación de contenidos multimedia e interactivos en la Pizarra Digital.

3-Propiciar actividades interactivas sobre los contenidos trabajados en la parte expositiva de la presentación de contenidos por parte del profesor.

4-Facilitar la creatividad en los trabajos sugeridos a los alumnos que pueden realizar en los equipos informáticos del centro educativo o sus domicilios y presentar, posteriormente, en el aula con la Pizarra Digital.

Posteriormente quisimos investigar sobre el impacto de la utilización de los recursos interactivos en el aprendizaje de los alumnos. De manera generalizada, nuestros profesores colaboradores valoran en muy alto grado la interactividad como valor añadido de la Pizarra Digital sobre otras herramientas y recursos tecnológicos utilizados en nuestras aulas.

En la actualidad investigamos y trabajamos sobre los nuevos modelos pedagógicos derivados de la utilización de la Pizarra Digfital y recursos y herramientas que se incorporan fácilmente en la labor docente: la Web 2.0, los trabajos colaborativos, las cámaras de documentos...

\section{8.- CÓMO ELEGIR UNA PIZARRA DIGITAL}

Contamos con un buen número de proveedores tecnológicos que nos facilitan modelos adaptados para cada necesidad educativa y también para casi todos niveles de presupuestos. Recorrer este abanico de ofertas iniciado en 1991 por Smart Technologies de Canadá y actualmente seguido por Promethean, TeamBoard, CleverBoard, Panasonic y otras empresas es, sin duda, una excelente forma de conocer el amplio campo de

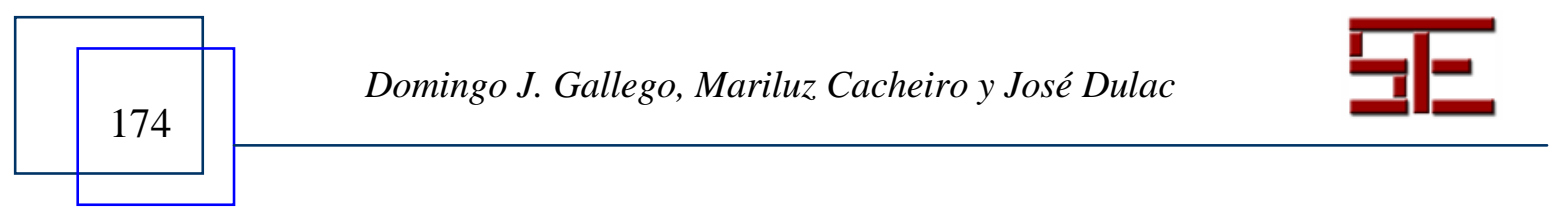




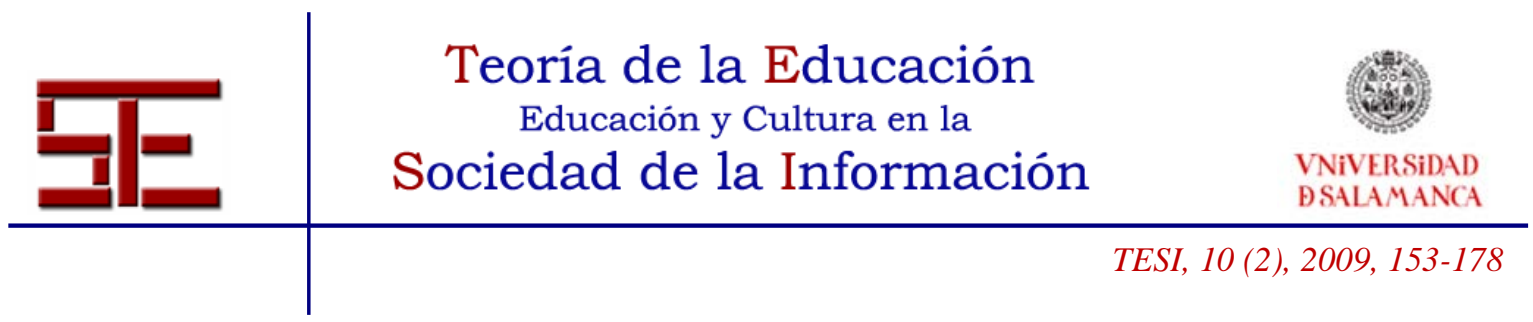

recursos que se ofrecen a los docentes, desde los más complejos y de tecnología más sofisticada, hasta los más sencillos como son el modelos que familiarmente llamamos “Croisan”, eBeam, o las adaptaciones de un WII que permiten trasladar el formato de pizarra digital a cualquier lugar a mínimo coste.

No podemos afirmar de manera absoluta que una determinada marca de PDI sea siempre la más conveniente, la más adecuada... la mejor para satisfacer las necesidades de todos. El análisis de las necesidades, las circunstancias, el contexto, las ofertas, sensibilidad de la PDI, rapidez de respuesta, software adicional, servicio técnico, etc. nos permitirán tomar una decisión adecuada.

Dentro del debate del foro DIM sobre Pizarras Digitales Manuel G. Vuelta (15/04/08) presentaba algunas sugerencias:

- Si queremos que alumnos de educación infantil toquen la pizarra con sus manos, no cabe duda que la pizarra táctil es la más adecuada.

- Si intentamos mayor robustez y trabajar con lápiz, y que no exista la posibilidad de que se manejes solo con la mano, la tecnología.

- Electromagnética Activa o Pasiva resultará más útil.

- Si pretendemos que pueda ser utilizada como una pizarra tipo velleda o como una Pizarra copiadora o como una Interactiva, así como imprimir a la máxima calidad y que pueda utilizarse un rotulador y que, si se escribe con un bolígrafo o con un indeleble, se pueda borrar fácilmente, no cabe duda que la adecuada será la que utilice Tecnología Electromagnética.

- Pasiva.

- Si desearíamos ponerla sobre cualquier pizarra velleda y que sea portable, la tecnología Ultrasónica + Infrarrojos podría ser adecuada.

- Si lo que se desea es convertir cualquier superficie en una Pizarra.

- Interactiva, sea ésta una pared, una velleda, una pantalla enrollable, la pantalla de una sala de actos, un monitor de plasma, preparar los ejercicios interactivos en el despacho o en casa o hacer tutorías a distancia, sin necesidad de video proyector, no cabe duda que la solución es la tecnología Electromagnética Pasiva en formato pequeño y portátil (una PDiP) con Bluetooth.

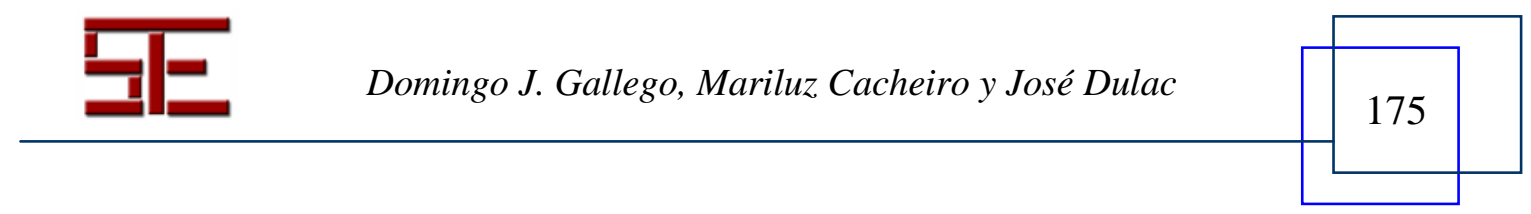




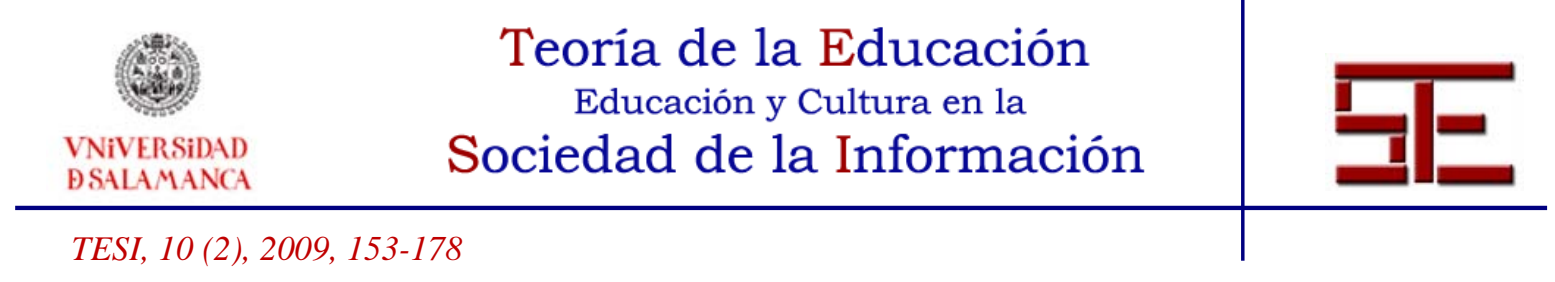

\section{9.- CONCLUSIÓN}

Desde la observación personal de docentes/usuarios de PDI en los últimos cinco años y tras el análisis detenido de las investigaciones, podemos afirmar que la PDI se incorpora al abanico de recursos tecnológicos que puede utilizar el docente, con un importante nivel de posibilidades tecno pedagógicas, creativas e innovadoras que se aumentan y fortalecen cuando se ofrece una formación adecuada a los profesores. La inversión en equipos debe ir siempre acompañada por la inversión en formación. Los equipos son imprescindibles pero servirán de poco sin facilitar la formación a los docentes.

\section{REFERENCIAS}

Alconada, C., Dulac, J., Gallego, D. y Cacheiro, M.L. (2007). Pizarra Digital y Tecnología Educativa. Consulta en http://www.teleuned.com/teleuned2001/directo.asp?ID=2658\&Tipo=C.

BECTA. Agencia gubernamental del Reino Unido para el uso de las TIC. Consulta el 07/03/2009 en http://www.becta.org.uk.

Bell, M.A. (2002). Why use an Interactive whiteboard? http://teachers.net/gazette/JAN02/mabell.html.

Dulac, J. (2006). La Pizarra Digital, ¿Una nueva metodología en el aula? Consulta el 5/04/2009 http://www.dulac.es/investigaciones/pizarra/Informe\%20final.\%20Web.pdf.

Fun-Encuentro. Fundación Encuentro. Consulta el 5/04/2009 en http://www.fundencuentro.org.

GP@. Grupo Pizarr@ para la formación e investigación sobre la Pizarra Digital Interactiva. Consulta 1/04/2009 en http://www.dulac.es/

Gallego, D. y Dulac, J. (2005). Informe final del Iberian Research Project. Consulta el 5/04/2009 en http://www.dulac.es/Iberian\%20research/Informe\%20final.doc

Gerard, F. y Otros (1999). SITE. San Antonio, Texas.

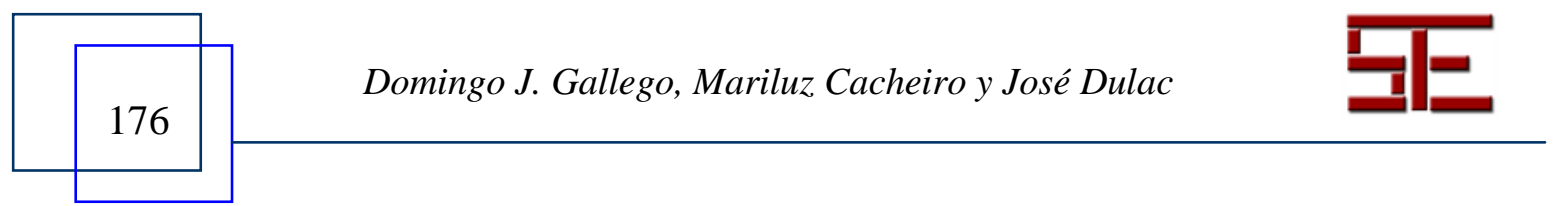




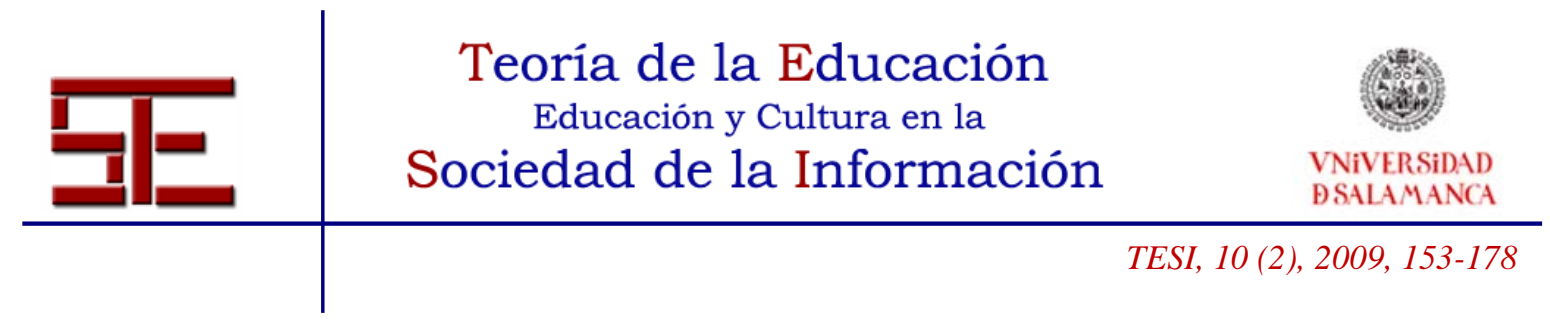

Glover, D. y Miller, D. (2001). Running with technology: the pedagogic impact of the large-scale introduction of interactive whiteboards in one secondary school. Journal of Information Technology for Teacher Education 10, 3, 257-276.

Goodison, T.A.M. (2002). Learning with ICT at primary level pupils’s perceptions. Journal of Computer Assisted Learning 18, 282-295.

Groupvision. Web de la distribuidora para España y Portugal de la pizarra digital interactiva de Smart Technologies. Consulta el 5/04/2009 en http://www.groupvision.es y http://www.aprenderconsmart.org.

Kennewell, S. (2001). Interactive whiteboards - yet another solution looking for a problem to solve? Information Technology in Teacher Education, 30. Autumm 2001. 36.

Levy, P. (2002). Interactive whiteboards in learning and teaching in two Sheffield Schools: a developmental study. Sheffield: Departament of Information Studies. University of Sheffield.

Marquès, P. (2009). La pizarra digital interactiva. Consulta el 5/04/2009 en http://dewey.uab.es/pmarques/pdigital/es/pizinteractiva.htm.

Marzano, R. Interactive Whiteboards $\quad$ (IWBs) trinity.ptly.com/index.php?id=869\&tx_ttnews\%5Btt_news\%5D=615\&tx_ttnews\%5Bba ckPid\%5D.

NCEF, National Clearinghouse for Educational Facilities http://www.ncef.org/rl/interactive_whiteboard.cfm.

Pradas, S. (2005). Propuestas para el uso de la Pizarra Digital Interactiva con el Modelo CAIT. Madrid: Fundación Encuentro.

Smarrtech. Grupo Smart Technologies. Empresa de Pizarras Digitales Interactivas Smart Technologies. Consulta el 5/04/2009 en http://www.smarttech.com.

Smith, A. (1999). Interactive whiteboard evaluation. http://www.mirandanet.ac,uk/pubs/smartboards.htm.

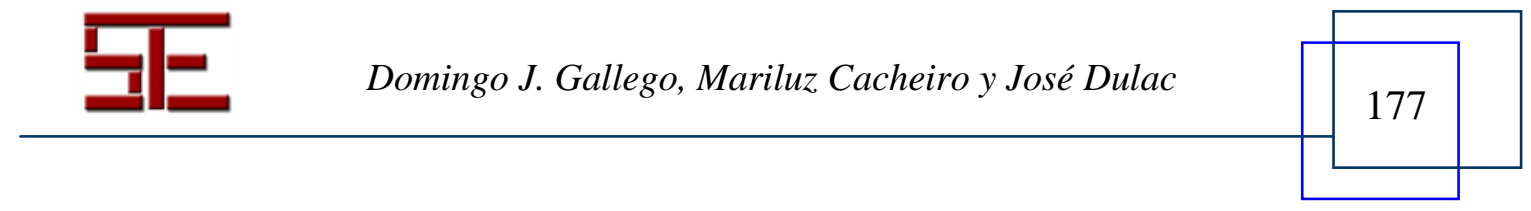




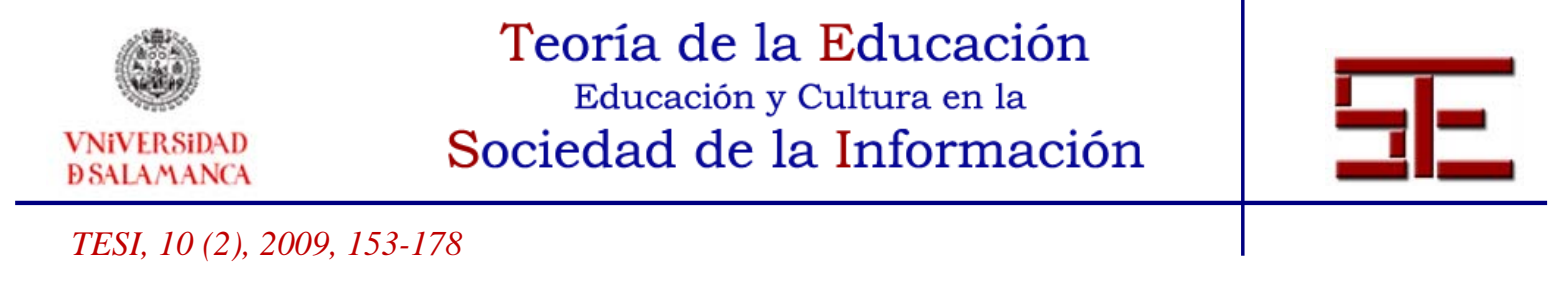

Smith, H. (2001). Smartboard evaluation: Final report. http://www.kented.org.uk/ngfl/whiteboards/report.html.

Somekh, B. et al. (2007). Evaluation of the Primary Schools Whiteboard Expansion Project. Report to the Department for Children, Schools and Families. Centre for ICT, Pedagogy and Learning Education \& Social Research Institute, Manchester Metropolitan University. UK: BECTA. Consulta 5/04/2009 en http://partners.becta.org.uk/uploaddir/downloads/page_documents/research/whiteboards _expansion.pdf.

UNED. Universidad Nacional de Educación a Distancia. Consulta el 5/04/2009 en http://www.uned.es/infoedu.

Walker, D. (2002). White enlightenling. Times Educational Supplement 13 september 2002. 19.

Walker, D. (2003). Quality at the dockside. TES Online pp. 66-67.

Para citar la presente editorial puede utilizar la siguiente referencia:

Gallego, G. Cacheiro, M. L. \& Dulac, J. (2009). La pizarra digital interactiva como recurso docente, en Ortega Sánchez, I. Ferrás Sexto, C. (Coord.) Alfabetización Tecnológica y desarrollo regional [monográfico en línea]. Revista Electrónica Teoría de la Educación: Educación y Cultura en la Sociedad de la Información. Vol. 10, nº 2. Universidad de Salamanca [Fecha de consulta: dd/mm/aaaa].

http://campus.usal.es/ revistas_trabajo/index.php/revistatesi/article/view/7512/7543

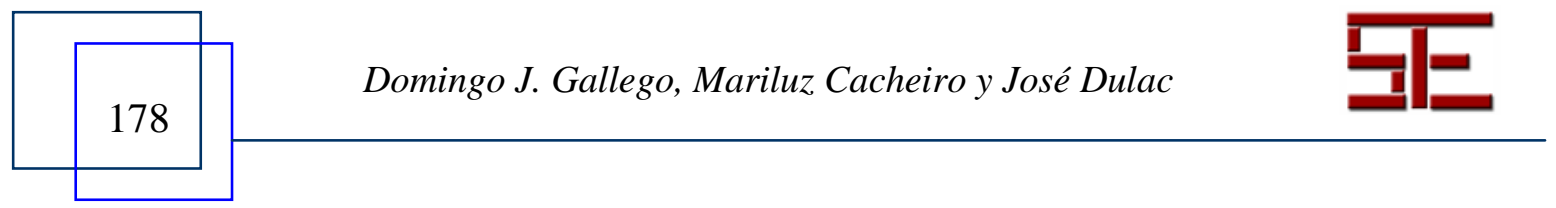

